\title{
Cortisol and Cytokines in Chronic and Treatment-Resistant Patients with Schizophrenia: Association with Psychopathology and Response to Antipsychotics
}

\author{
Xiang Yang Zhang*, 1,2,3, Dong Feng Zhou', Lian Yuan $\mathrm{Cao}^{2}$, Gui Ying $\mathbf{W u}^{2}$ and Yu Cun Shen' \\ 'Institute of Mental Health, Peking University, Beijing, PR China; ${ }^{2}$ Beijing Hui-Long-Guan Hospital, Beijing, PR China; ${ }^{3}$ Department of Psychiatry, \\ Yale University School of Medicine, New Haven, CT, USA
}

\begin{abstract}
The bilateral communication between the immune and neuroendocrine systems plays an essential role in modulating the adequate response of the hypothalamic-pituitary-adrenal (HPA) axis to the stimulatory influence of cytokines and stress-related mediators. Growing evidence suggests that neuro-immune-endocrine crosstalk may be impaired in schizophrenia. We determined the relationship between cortisol, cytokines interleukin-2 (IL-2) and interleukin-6 (IL-6), and symptoms in schizophrenia during treatment with typical and atypical antipsychotic drugs. Subjects included 30 healthy controls $(\mathrm{HC})$ and 78 schizophrenic $(\mathrm{SCH})$ in-patients. $\mathrm{SCH}$ were randomly assigned to 12 -week treatment with $6 \mathrm{mg} /$ day of risperidone or $20 \mathrm{mg} /$ day of haloperidol using a double-blind design. Clinical efficacy was determined using the Positive and Negative Syndrome Scale (PANSS). Serum cortisol and IL-2 levels were assayed by radioimmunometric assay, and serum IL-6 levels by quantitative enzyme-linked immunosorbent assay. Following a 2-week washout period, serum levels of cortisol, IL-2, and IL-6 were increased in patients with schizophrenia compared to HC. Elevations in cortisol were associated with increase in both IL-2 and IL-6 in SCH. Moreover, elevations in cortisol were associated with negative symptoms and IL-2 with positive symptoms. In all, 12 weeks of risperidone treatment significantly decreased elevated cortisol and improved negative symptoms, but produced similar effects on IL-2 and IL-6 as well as on positive symptoms compared to haloperidol. The improvement of negative symptoms was related to the change in cortisol. Our results suggest that the imbalance in the HPA axis and cytokine system in patients with $\mathrm{SCH}$ is implicated in clinical symptoms, and is improved with atypical antipsychotic treatment.

Neuropsychopharmacology (2005) 30, I532-1538, advance online publication, I I May 2005; doi: I 0. I 038/sj.npp. I 300756
\end{abstract}

Keywords: schizophrenia; immune; interleukin; cortisol; psychopathology; antipsychotic; hypothalamic-pituitary-adrenal (HPA) axis

\section{INTRODUCTION}

There is a complex bidirectional communication between the nervous, endocrine, and immune systems that can be demonstrated by the presence of shared neurotransmitters, hormones, and cytokines (Blalock, 1989; Haddad et al, 2002). Communication between these systems plays an essential role in modulating the adequate response of the hypothalamic-pituitary-adrenal (HPA) axis to the stimulatory influence of cytokines and stress-related mediators

\footnotetext{
*Correspondence: Dr XY Zhang, Department of Psychiatry, Yale University School of Medicine, Building 5, 3rd Floor, VA Connecticut Healthcare System, 950 Campbell Ave, West Haven, CT 065 I6, USA, Tel: + I 203932 57II ext. 4I33, Fax: + I 2039747897 ,

E-mail: zhangxy9@yahoo.com

Received 30 November 2004; revised 22 February 2005; accepted 24 March 2005

Online publication: 3I March 2005 at http://www.acnp.org/citations/ Npp033 105040559/default.pdf
}

(Spangelo et al, 1995). Growing evidence suggests that, in addition to providing communication between immune cells, specific cytokines play a role in signaling the brain to produce neurochemical, neuroendocrine, neuroimmune, and behavioral changes (Muller and Ackenheil, 1998; Kronfol and Remick, 2000). Recently, studies have shown that the interface between these complex systems is impaired in schizophrenia (SCH, Altamura et al, 1999). Specially, $\mathrm{SCH}$ has been associated with several immunological abnormalities, including decreased mitogen-induced lymphocyte proliferation (Chengappa et al, 1995), altered numbers of total T and T-helper cells (Muller et al, 1993), the presence of antibrain antibodies in serum (Henneberg et al, 1994), and changes in cytokines and cytokine receptors in the blood and the cerebrospinal fluid (CSF) (Licinio et al, 1993; Rapaport et al, 1994, 1997; Ganguli et al, 1994, 1995; Maes et al, 1995, 1997, 2000, 2002; Lin et al, 1998; Arolt et al, 2000; Zhang et al, 2002a,b). Together, these studies show that $\mathrm{SCH}$ is associated with significant immunological alterations, and activation of the 
inflammatory response system (IRS) is mediated, in part, by cytokines. Interestingly, these abnormalities are particularly prominent in treatment-resistant SCH (Lin et al, 1998; Maes et al, 2000, 2002).

Evidence also suggests dysfunction in the HPA axis in SCH (Walker and Diforio, 1997; Marx and Lieberman, 1998). Abnormalities in the HPA axis of SCH have been shown using the dexamethasone suppression test (DST). Nonsuppression, due to the lack of glucocorticoid secretion feedback mechanisms, occurs frequently in $\mathrm{SCH}$, with percentages varying between 11 and 55\% (Sharma et al, 1988; Yeragani, 1990; Coryell and Tsuang, 1992). Moreover, several studies showed that basal cortisol levels are significantly higher in schizophrenic (SCH) patients compared to normal controls (Walker and Diforio, 1997; Lammers et al, 1995), although these findings have not been consistent between studies (Jansen et al, 1998; Kaneda et al, 2002). Studies also suggest a relationship between HPA activity and symptomatology in SCH. Cortisol secretion has been associated with more severe positive symptoms (Kaneko et al, 1992; Walder et al, 2000), whereas in others it was associated with higher ratings of negative symptoms (Newcomer et al, 1991; Tandon et al, 1991). Some investigators purport that in $\mathrm{SCH}$, there is an association of DST nonsuppression with negative symptoms (Altamura et al, 1989; Newcomer et al, 1991; Tandon et al, 1991). Taken together, these results suggest that HPA axis dysregulation/activation and hypercortisolemia are frequent present in $\mathrm{SCH}$ patients.

Wang and Dunn (1999) reported that HPA axis activation can be elicited by exogenous cytokines, such as interleukin1 (IL-1), IL-6 when administered to rodents. Several cytokines are also known to affect the release of anterior pituitary hormones by an action on the hypothalamus and/ or the pituitary glands (Bumiller et al, 1999). Moreover, as mentioned previously, $\mathrm{SCH}$ is associated with a hyperresponsive IRS. Therefore, Altamura et al (1999) proposed the hypothesis that hypercortisolemia observed in $\mathrm{SCH}$ could be induced by cytokines. So far, however, this association remains to be elucidated.

In view of the previously mentioned studies and the close relationship between HPA axis and immune system, we tested the hypothesis that alterations in neuroendocrine systems may be related to changes in immune system in $\mathrm{SCH}$; changes that could be especially apparent in treatment-resistant $\mathrm{SCH}$. Also, we speculate that inappropriate interaction of HPA axis and cytokines might play a role in the pathogenesis of some symptoms occurring in $\mathrm{SCH}$. Further, we wanted to determine if typical or atypical antipsychotics-induced effects on HPA axis and IRS could account for the differences in clinical response, which, to our knowledge, has not been investigated so far. Therefore, the purpose of the study was to investigate whether (1) serum cortisol, IL-2, and IL-6 were increased simultaneously in chronic and treatment-resistant schizophrenic patients; (2) there was a relation between cortisol and cytokines, or between symptom severity and both cortisol and cytokines; (3) there was a significant difference between typical and atypical antipsychotic drugs in the influence on the serum cortisol, IL-2, and IL-6; (4) there were any relationships between the changes of serum cortisol, IL-2, and IL- 6 and the changes of psychopathological symptoms.

\section{METHODS AND SUBJECTS}

\section{Subjects}

Physically healthy Chinese in-patients were diagnosed as meeting the Diagnostic and Statistical Manual of Mental Disorders (DSM-III-R) criteria for SCH, using the Structured Clinical Interview for DSM-III-R (SCID). All patients were considered resistant to treatment if meeting the following criteria: no response to at least three antipsychotics treated 3 months or over at full dose, equivalent to chlorpromazine $800 \mathrm{mg} /$ day. Both patients and 30 normal volunteers were recruited at the same period from Beijing area. Normal controls were recruited from the community, and matched for age and gender. Both patients and matched normal subjects had similar socioeconomic status. Demographic data for patients and normal controls are summarized in Table 1.

All subjects gave informed written consent to participate in the study, which was approved by the Institutional Review Board, the Institute of Mental Health, Peking University. They were screened with a complete physical, neurological, and psychiatric evaluation conducted by the clinical physicians. None of the SCH patients nor control subjects suffered from substance abuse/dependence or were receiving immunosuppressive drugs.

\section{Clinical Treatment and Clinical Ratings}

Clinical treatment and ratings have been described in detail in our earlier report (Zhang et al, 2001). Briefly, the clinical trials consisted of a 2-week placebo lead-in followed by 12 weeks of double-blind treatment. Medications that patients had been taking prior to the 2-week washout period were either clozapine $(n=20)$, perphenazine $(n=17)$, chlorpromazine $(n=16)$, haloperidol $(n=15)$, thioridazine $(n=6)$, or sulpiride $(n=4)$. A total of 78 patients were randomized into risperidone group $(n=41)$ and haloperidol group $(n=37)$. The dose of risperidone was increased to $6 \mathrm{mg} / \mathrm{day}$ and the dose of haloperidol to $20 \mathrm{mg}$ /day during the first week of blind administration, and the doses were maintained at those levels until the end of the trial.

The Positive and Negative Syndrome Scale (PANSS) (Kay et al, 1987) was administered by four clinical psychiatrists who were blind to the treatment. To ensure consistency and

Table I Demographics of Patients and Normal Control Subjects

\begin{tabular}{lccc}
\hline & $\begin{array}{c}\text { Risperidone } \\
(\mathbf{n}=\mathbf{4 I})\end{array}$ & $\begin{array}{c}\text { Haloperidol } \\
(\mathbf{n}=\mathbf{3 7})\end{array}$ & $\begin{array}{c}\text { Control } \\
\text { subjects }(\mathbf{n}=\mathbf{3 0})\end{array}$ \\
\hline Sex, M/F & $30 / 11$ & $30 / 7$ & $22 / 8$ \\
Age (years) & $43.8 \pm 6.4$ & $43.7 \pm 8.1$ & $40.4 \pm 10.3$ \\
$\begin{array}{l}\text { Duration of illness } \\
\text { (years) }\end{array}$ & $21.6 \pm 10.9$ & $19.2 \pm 9.4$ & $\mathrm{NA}$ \\
Smokers & $28(68 \%)$ & $24(65 \%)$ & $19(63 \%)$ \\
Smoked cigarettes & $12.4 \pm 8.3$ & $12.1 \pm 8.1$ & $11.9 \pm 5.0$ \\
\hline
\end{tabular}

All data were reported as mean \pm SD unless otherwise indicated. There were no significant differences among risperidone, haloperidol and control groups on any characteristic by $\chi^{2}$ test and analysis of variance (ANOVA), followed by post hoc tests (Fisher's LSD test). 
reliability of ratings across study, four psychiatrists attended a training session in the proper use of the PANSS before study began. After training, a correlation coefficient greater than 0.8 was maintained for the PANSS total score by repeated assessments.

\section{Cortisol Assay}

Serum samples of patients were collected between 0700 and $0900 \mathrm{~h}$ at the end of the 2-week washout period and after 12week treatment. Samples from healthy controls were collected at the same period as that of the patients at the end of washout period. The serum was separated via centrifugation, aliquoted and stored at $-70^{\circ} \mathrm{C}$ until assayed.

Serum cortisol was determined by radioimmunometric assay (RIA). The assay was performed in accordance with the manufacturer's instructions (Tianjin DePu Inc., China). Each sample was run in duplicate. The sensitivity was $1 \mathrm{ng} /$ $\mathrm{ml}$, intra- and inter-assay variation coefficients were 6 and $10 \%$, respectively.

\section{Measurement of Serum IL-2 and IL-6}

IL-2 was assayed in serum by RIA (ChangZheng Inc., Chinese Second Military Medical University, Shanghai, China). The assay was performed in accordance with the manufacturer's instructions. Each assay was run in duplicate. The sensitivity was $0.2 \mathrm{ng} / \mathrm{ml}$, intra- and inter-assay variation coefficients were 6 and $8 \%$, respectively.

Serum IL-6 levels were measured in duplicate by sandwich ELISA using a commercially available kit (BanDing Biological Inc., Chinese Academy of Sciences, Beijing, China). The sensitivities were $0.2 \mathrm{ng} / \mathrm{ml}$, and intra- and inter-assay variation coefficients were 7 and $9 \%$, respectively.

All samples were assayed by the same investigator who was blind to the treatment condition.

\section{Statistical Analyses}

Since the majority of the interleukin variables were not normally distributed in patients (Kolmogorov-Smirnov one-sample test), and although all these variables were normally distributed in normal controls, the principal analysis consisted of nonparametric tests for comparison between groups of patient and normal control (MannWhitney). Since serum cortisol was normally distributed in both patients and normal controls, analysis of variance (ANOVA) was used. Analysis of covariance (ANCOVA) was also performed, using age, duration of illness, baseline cortisol level, baseline PANSS score as covariates, followed by Fisher's least significant difference (LSD) test to compare the differences in cortisol levels between the groups. Correlation among cortisol, IL-2, and IL-6 levels and clinical ratings were examined by bivariate correlation (Spearman or Pearson correlation coefficients). Where there was a significance, the Bonferroni correction was used if necessary. Total PANSS scores and its subscores, cortisol, IL-2, and IL-6 levels were examined by multivariate regression analyses. All statistical tests were two-tailed and were considered to be statistically significant at $p<0.05$.

\section{RESULTS}

\section{Demographic Data}

Table 1 shows characteristics of the patients and normal controls. No significant relationships between age or sex and serum IL-2, IL-6, or cortisol were noted either for the whole group, or when the normal controls and patients were examined separately. Age of onset of psychosis, duration of illness, and hospitalization did not significantly correlate with IL-2, IL-6, and cortisol levels in the patient group.

\section{Clinical Results}

Table 2 showed statistically significant differences between baseline and after 12 weeks of treatment with either risperidone or haloperidol. Both drugs improved PANSS total scores and all subscore measures $(p<0.01-0.001)$. Further comparison between risperidone and haloperidol show that risperidone showed greater improvement on PANSS total score $(p=0.03)$ and the general psychopathology subscore $(p=0.01)$.

\section{Changes of Serum IL-2, IL-6, and Cortisol before and after Treatment}

IL-2 was detected in 72 patients $(92.3 \%)$ and 26 controls $(86.7 \%)$, and IL-6 in 55 patients $(70.5 \%)$ and 16 controls (53.3\%). IL-2 and IL-6 not detected in patients or normal control subjects were not included in the analysis.

Serum cortisol was significantly lower in healthy controls $(72.2 \pm 24.7 \mathrm{ng} / \mathrm{ml})$ compared to patients at baseline

Table 2 Comparison of Scores at Baseline and Week 12 on the Total and Subscores of PANSS in Risperidone and Haloperidol Groups

\begin{tabular}{|c|c|c|c|c|c|}
\hline & Baseline & Week I2 & $\mathbf{F}^{\mathrm{a}}$ & $d f^{a}$ & $p^{a}$ \\
\hline \multicolumn{6}{|c|}{ PANSS total score } \\
\hline Risperidone & $82.4 \pm 22.4$ & $61.8 \pm 20.6$ **** & 4.98 & ।,70 & 0.03 \\
\hline Haloperidol & $79.2 \pm 21.7$ & $64.7 \pm 16.6$ ***** & & & \\
\hline \multicolumn{6}{|l|}{ P-subscore } \\
\hline Risperidone & $17.9 \pm 7.5$ & $12.9 \pm 6.5$ ***** & 2.15 & ।,70 & 0.14 \\
\hline Haloperidol & $15.3 \pm 7.9$ & | I. $4 \pm 5.8^{*} * * * * *$ & & & \\
\hline \multicolumn{6}{|l|}{ N-subscore } \\
\hline Risperidone & $26.6 \pm 8.7$ & $22.1 \pm 8.5^{* * * * *}$ & 3.57 & ।,70 & 0.056 \\
\hline Haloperidol & $28.1 \pm 5.9$ & $24.6 \pm 5.5^{*} * *$ & & & \\
\hline \multicolumn{6}{|l|}{ G-subscore } \\
\hline Risperidone & $37.9 \pm 11.5$ & $26.7 \pm 8.7$ ***** & 6.92 & ।,70 & 0.01 \\
\hline Haloperidol & $36.1 \pm 11.8$ & $28.6 \pm 8.5$ ***** & & & \\
\hline
\end{tabular}

PASS, Positive and Negative Syndrome Scale; P-subscore, positive symptom subscore; N-subscore, negative symptoms subscore; G-subscore, general psychopathology subscore.

${ }^{\mathrm{a}} \mathrm{F}$ values and $\mathrm{p}$ are related to comparison between risperidone and haloperidol groups at week 12 .

*Comparison between pre- and post-treatment. ${ }^{*} p p<0.0$ I, ${ }^{*} * * * * 0.00$ I. 
concentrations $(103.2 \pm 42.3 \mathrm{ng} / \mathrm{ml}$; ANOVA $)$ and at posttreatment $\left(77.9 \pm 30.7 \mathrm{ng} / \mathrm{ml} ; \chi^{2}=22.69, \quad \mathrm{df}=2, p<0.01\right)$. Serum cortisol concentrations in $\mathrm{SCH}$ patients were significantly lower after treatment compared to before treatment (Wilcoxon's test, $Z=-10.45, p<0.01$ ). Baseline levels of IL-2 in healthy controls $(3.3 \pm 1.4 \mathrm{ng} / \mathrm{ml})$ were significantly lower compared to $\mathrm{SCH}$ subjects $(9.6 \pm 5.2$ $\mathrm{ng} / \mathrm{ml})$ even at post-treatment $\left(6.7 \pm 4.6 \mathrm{ng} / \mathrm{ml} ; \chi^{2}=11.89\right.$, $\mathrm{df}=2, p<0.01)$. Finally, serum IL-2 concentrations in SCH patients were significantly lower after treatment (Wilcoxon's test, $Z=-4.33, p<0.01$ ).

Table 3 shows a significantly lower cortisol level at posttreatment in risperidone group compared to the haloperidol group $(Z=-2.46, p<0.05)$. In addition, no significant difference in IL-6 concentrations was noted between before and after treatment for both groups (all $p>0.05$ ). Both risperidone and haloperidol significantly decreased cortisol and IL-2 levels compared to baseline (see Table 3).

\section{Relationship among Cortisol, IL-2, and IL-6}

Table 4 demonstrates a positive correlation between cortisol and IL-2 $(r=0.36, \mathrm{df}=75, p<0.01)$ and IL-6 $(r=0.41$,

Table 3 Comparison of Serum Cortisol, IL-2 and IL-6 Levels at Baseline and Week 12 in Risperidone and Haloperidol Groups $(\mathrm{ng} / \mathrm{ml})$

\begin{tabular}{lcccc}
\hline & Baseline & Week I2 & Z & P \\
\hline Cortisol & & & & \\
Risperidone & $104.2 \pm 44.9$ & $72.0 \pm 31.7^{*}$ & -3.27 & 0.002 \\
Haloperidol & $106.2 \pm 41.7$ & $83.8 \pm 28.6$ & -2.84 & 0.005 \\
& & & & \\
IL-2 & & & & \\
Risperidone & $9.8 \pm 4.7$ & $7.2 \pm 4.9$ & -3.46 & 0.0015 \\
Haloperidol & $9.9 \pm 5.2$ & $6.1 \pm 4.3$ & -3.64 & 0.001 I \\
& & & & \\
IL-6 & & & & \\
Risperidone & $0.3 \pm 0.5$ & $0.23 \pm 0.4$ & -0.24 & 0.68 \\
Haloperidol & $0.2 \pm 0.3$ & $0.17 \pm 0.2$ & -0.11 & 0.92 \\
\hline
\end{tabular}

Note: * indicates comparison between risperidone vs haloperidol, $* p=0.014$.

Table 4 Intercorrelations between Cortisol, IL-2 and IL-6 in Patients with Schizophrenia before and after 12-Week Treatment

COR TI COR T2 IL-2 TI IL-2 T2 IL-6 TI IL-6 T2

\begin{tabular}{lllllll}
\hline COR TI & - & & & & & \\
COR T2 & 0.12 & - & & & & \\
IL-2TI & $0.36 * *$ & 0.16 & - & & \\
IL-2T2 & 0.17 & 0.04 & $0.41 * *$ & - & & \\
IL-6TI & $0.41 *$ & -0.03 & 0.06 & 0.17 & - & \\
IL-6T2 & 0.11 & 0.12 & 0.15 & 0.12 & $0.38 * *$ & - \\
\hline
\end{tabular}

***Correlation is significant at the 0.01 level.

Note: TI and T2 indicate the cortisol and interleukin levels at baseline and at post-treatment. $\mathrm{df}=75, p<0.01)$ in the SCH group. Serum IL-2 and IL-6 $(r=0.42, \mathrm{df}=30, p<0.05)$ and serum IL-6 and cortisol were also positively corrected in healthy controls $(r=0.38$, $n=30, p<0.05)$.

\section{Relation between Cortisol, IL-2, or IL-6 and Clinical Symptoms at Pre- and Post-Treatment}

The results from Table 5 suggest that cortisol levels were indeed associated with negative symptomology. In addition, IL-2 levels were negatively correlated with PANSS positive subscore $(r=-0.31, \mathrm{df}=71, p<0.01)$ at pretreatment.

\section{Relation of Cortisol and Cytokines with Clinical Outcome}

Reduction in PANSS total score and its subscores after treatment determined the efficacy of antipsychotic drugs. The change of IL-2, IL-6, and of cortisol refers to the values of these parameters before treatment minus their respective values after treatment.

The results showed that there was a significant correlation between the reduction of PANSS total score and the change of IL-2 before and after treatment $(r=0.38, \mathrm{df}=65$, $p<0.01)$ or cortisol levels at post-treatment $(r=-0.36$, $\mathrm{df}=67, p<0.01)$. Reduction in PANSS positive subscore was negatively correlated with serum IL-2 at baseline $(r=-0.36, \mathrm{df}=67, p<0.01)$. Moreover, the reduction of PANSS negative subscore was associated with decrease in serum cortisol between pre- and post-treatment $(r=0.34$, $\mathrm{df}=69, p<0.01)$. No correlations were observed between the change of IL- 6 before and after treatment and the reduction of the PANSS total score and its subscores (all $p>0.05)$.

A set of regression analyses was conducted in order to identify the possible contribution of the cortisol, IL-2, and IL-6 to clinical outcome (as defined by the reduction of PANSS total score). A simultaneous entry regression analysis was conducted first, with age, sex, duration of illness, and measures of cortisol, IL-2, and IL- 6 at both preand post-treatment, as well as the changes in cortisol, IL-2, and IL-6 between pre- and post-treatment as dependents. The overall analysis was statistically significant $(R=0.707$, $\left.R^{2}=0.50, F=3.77, p=0.002\right)$. When this analysis was repeated with a forward entry stepwise regression analysis, sex was entered into the regression equation first $(\beta=0.45$, $t=3.26, \quad p=0.002)$, and accounted for $18.3 \%$ of the variance, followed by IL-2 levels at baseline $(\beta=-0.33$, $t=-2.56, p=0.014)$ and the change in cortisol between pre- and post-treatment $(\beta=0.26, t=2.04, p=0.048)$, which accounted for 9.5 and 5.2\%, respectively.

\section{DISCUSSION}

Elevated levels of cortisol in SCH found in the present study are in agreement with some previous studies (Newcomer et al, 1991; Tandon et al, 1991; Lammers et al, 1995; Meltzer et al, 2001), but not with others (Jansen et al, 1998; Kaneda et al, 2002). Our finding of positive correlation between cortisol and negative symptoms is consistent with some previous studies (Newcomer et al, 1991; Tandon et al, 1991; Shirayama et al, 2002). In contrast, some other studies 
Table 5 Intercorrelations between Cortisol, IL-2 and IL-6 and Clinical Variables in Patients with Schizophrenia before and after I2-Week Treatment

\begin{tabular}{lccrrrr}
\hline & COR TI & CORT2 & IL-2TI & IL-2T2 & IL-6TI & IL-6T2 \\
\hline Age & $-0.15(028)$ & $0.13(0.36)$ & $0.04(0.78)$ & $0.06(0.66)$ & $0.02(0.87)$ & $0.02(0.88)$ \\
Duration of illness & $0.06(0.67)$ & $-0.05(0.73)$ & $-0.01(0.95)$ & $0.02(0.91)$ & $0.13(0.34)$ & $0.15(0.31)$ \\
PANSS total score (TI) & $0.17(0.17)$ & $-0.04(0.72)$ & $-0.19(0.12)$ & $-0.01(0.93)$ & $-0.11(0.39)$ & $-0.09(0.43)$ \\
PANSS positive (TI) & $0.05(0.69)$ & $-0.12(0.34)$ & $-0.31(0.01) *$ & $-0.08(0.51)$ & $-0.01(0.93)$ & $-0.06(0.59)$ \\
PANSS negative (TI) & $0.28(0.02) *$ & $0.04(0.77)$ & $0.03(0.84)$ & $0.08(0.5 I)$ & $0.07(0.56)$ & $0.06(0.62)$ \\
PANSS total score (T2) & $0.03(0.78)$ & $0.30(0.01)^{*}$ & $-0.18(0.15)$ & $-0.08(0.52)$ & $0.08(0.49)$ & $0.07(0.53)$ \\
PANSS positive (T2) & $0.14(0.24)$ & $0.03(0.84)$ & $0.11(0.35)$ & $-0.01(0.94)$ & $0.01(0.93)$ & $0.01(0.92)$ \\
PANSS negative (T2) & $-0.08(0.49)$ & $0.34(0.005) * *$ & $-0.12(0.32)$ & $-0.02(0.89)$ & $0.01(0.99)$ & $0.01(0.93)$ \\
\hline
\end{tabular}

Note: TI and T2 indicate the cortisol, interleukin levels, or PANSS scores at baseline and at post-treatment. The numbers in the parentheses indicate the p-value.

found a correlation between cortisol and positive symptoms (Kaneko et al, 1992; Walder et al, 2000). Differences in experimental methodology between studies may explain divergent studies. These include: differences in tested material (serum vs plasma), sampling of patients in different stages of disease progression (acute $v s$ chronic or active phase $v s$ remission), exposure to a variety and duration of neuroleptic treatments and different disease progression. Nevertheless, our results clearly show that cortisol is elevated in patients with $\mathrm{SCH}$ and this elevation is positively correlated with negative symptoms.

Some previous study found abnormalities in the cytokine system in treatment-refractory SCH patients (Lin et al, 1998; Maes et al, 2000). In our present study, we also found that levels of IL-2 and IL-6 were elevated in patients with treatment-refractory $\mathrm{SCH}$, suggesting again activation of the IRS. Moreover, serum IL-2 or IL-6 and cortisol were positively correlated in our $\mathrm{SCH}$ population providing support for the hypothesis that hypercortisolemia observed in $\mathrm{SCH}$ could be induced by proinflammatory cytokines (Altamura et al, 1999).

Cytokine IL-2 exerts numerous effects within the immune as well as the central nervous system and is thought to serve as a humoral signal in their communication. IL-2 plays a major role in regulating HPA axis action, which may occur at different levels of regulation (Haddad et al, 2002). For example, Hanisch et al (1994) found that IL-2 caused a significant increase in ACTH levels during the later portion of the dark phase of the cycle, and plasma corticosterone concentrations were significantly elevated over almost the entire diurnal cycle (Hanisch et al, 1994). An additional study showed that HPA axis activation can be elicited by exogenous cytokines (IL-1, IL-6, TNF- $\alpha$ ) when administered to rodents (Wang and Dunn, 1999). Injection of IL-6 into humans increases plasma adrenocorticotropic hormone and plasma cortisol (Bethin et al, 2000; Steensberg et al, 2003). Moreover, both the pituitary corticotrophs and adrenocortical cells express IL-6 receptors, and IL-6 increases cortisol both directly and indirectly (Bethin et al, 2000). Taken together, the data indicate that IL-2 and IL-6 are potent activators of the HPA axis, which provide additional evidence to support the hypothesis that hypercortisolemia in SCH may be mediated by the elevated cytokines.
Risperidone, which is more effective on negative symptoms, decreased cortisol serum levels more to a greater degree than haloperidol in the present study. Furthermore, the significant reduction of PANSS negative subscore and the change of cortisol level before and after treatment suggests that the improvement in negative symptoms is associated with the changes in serum cortisol levels. Taken together, these findings suggest that different clinical responses to atypical $v s$ typical neuroleptics, paralleled with their different effects on hypercortisolism, could offer an explanation of the additional efficacy on negative symptoms for the former drugs. In addition, it is worthy of mentioning that the effects of antipsychotic drugs on cortisol levels and/ or the negative symptoms may be not directly related to the changes in IL-2 or IL-6, because no significant relationships were found among these variables during treatment.

Risperidone is a relatively new atypical antipsychotic agent, with potent serotonin-5-HT2A and dopamine-D2 receptor blocking properties (Janssen et al, 1988). The superiority of risperidone over haloperidol on negative symptoms may be related to its antagonism of 5-HT2 in different brain areas (Wirshing et al, 1999; Geddes et al, 2000; Zhang et al, 2001). On the other hand, there is an increasing evidence that 5-HT promotes HPA axis activity at the hypothalamic, pituitary, and adrenal levels (Chaouloff, 1993; Dinan, 1996). Pharmacological stimulation of different 5-HT receptor subtypes as well as stress-induced 5-HT release promote activation of the HPA axis and subsequent release of $\mathrm{CRH}, \mathrm{ACTH}$, and glucocorticoids (Chaouloff, 1993). In relation to the present study, MuckSeler et al (1999) showed that SCH patients have a HPA axis dyregulation and that this may be related to abnormalities in the 5-HT system (Muck-Seler et al, 1999). Thus, risperidone's action at 5HT2 receptors may explain its greater efficacy on negative symptoms and its ability to decrease cortisol serum levels compared to the typical neuroleptic haloperidol.

Several points concerning the reliability of measuring IL-2 levels should be noted. Many researchers are not able to detect IL-2 levels in serum which is most likely due to the assay employed. We utilized radioimmuno-assay which detects pico-gram quantities of the target protein in question. This highly sensitive assay may be the reason we were able to detect IL-2 in SCH patients and in normal 
controls with significantly higher levels in patients. Another possible explanation is that there are significant differences in IL-2 genotype frequencies observed in different populations. Recent studies have shown that inheritance of polymorphic cytokine gene alleles is dramatically influenced by ethnicity (Cox et al, 2001; Hoffmann et al, 2002). Moreover, a statistically significant ethnicity-based variability in the allelic frequency and genotype inheritance patterns for IL-2 and IL-6 has been reported (Cox et al, 2001), suggesting that polymorphisms within these cytokine genes may be responsible for the ethnic-based differences in IL-2 or IL-6 levels. Unfortunately, there is no comparison study on the IL-2 genotype between Chinese and Caucasians. In regards to the present study, the possible effects of antipsychotic treatment before the washout period may play a role. Our patients had undergone chronic long-term treatment with antipsychotics. Studies have shown that typical and atypical antipsychotic drugs exert immunosuppressive effects on the production of cytokine (Maes et al, 1995; Song et al, 2000). IL-2 and IL-6 levels were measured after patients underwent a 2 -week washout period, thus it is possible that elevated levels is a rebound effect following drug withdrawal. To answer this question, future research should examine the effects of antipsychotics on cytokine levels in naive, first-episode $\mathrm{SCH}$ patients.

In summary, our results suggest that dysregulation in neuro-immune-endocrine systems exist and are linked to clinical symptoms of SCH. The differential effects of typical $v s$ atypical antipsychotics on the HPA axis and IRS in SCH could account, at least in part, for the better clinical outcome, especially for negative symptoms achieved in patients treated with the latter drugs compared to those receiving conventional neuroleptics.

\section{ACKNOWLEDGEMENTS}

We are grateful to Zhen Quan Guan and Li Sun for their technical assistance. Appreciation is also owed to the patients, clinical psychiatrists, and nursing staff of the Wards 1, 2, 4, 7, and 17, Beijing Hui-Long-Guan Hospital for their participation and collaboration. In addition, We thank Dr Colin Haile for his helpful revision on the manuscript. This study was supported by the Beijing Scientific and Technological New Stars Fund, Beijing, China (Dr XY Zhang).

\section{REFERENCES}

Altamura C, Guercetti G, Percudani M (1989). Dexamethasone suppression test in positive and negative schizophrenia. Psychiatry Res 30: 69-75.

Altamura AC, Boin F, Maes M (1999). HPA axis and cytokines dysregulation in schizophrenia: potential implications for the antipsychotic treatment. Eur Neuropsychopharmacol 10: 1-4.

Arolt V, Rothermundt M, Wandinger KP, Kirchner H (2000). Decreased in vitro production of interferon-gamma and interleukin-2 in whole blood of patients with schizophrenia during treatment. Mol Psychiatry 5: 150-158.

Bethin KE, Vogt SK, Muglia LJ (2000). Interleukin-6 is an essential, corticotropin-releasing hormone-independent stimulator of the adrenal axis during immune system activation. Proc Natl Acad Sci USA 97: 9317-9322.
Blalock JE (1989). A molecular basis for bidirectional communication between the immune and neuroendocrine systems. Physiol Rev 69: 1-32.

Bumiller A, Gotz F, Rohde W, Dorner G (1999). Effects of repeated injections of interleukin 1beta or lipopolysaccharide on the HPA axis in the newborn rat. Cytokine 11: 225-230.

Chaouloff F (1993). Physiopharmacological interactions between stress hormones and central serotonergic systems. Brain Res Brain Res Rev 18: 1-32.

Chengappa KN, Ganguli R, Yang ZW, Shurin G, Brar JS, Rabin BS (1995). Impaired mitogen (PHA) responsiveness and increased autoantibodies in Caucasian schizophrenic patients with the HLA B8/DR3 phenotype. Biol Psychiatry 37: 546-549.

Coryell W, Tsuang D (1992). Hypothalamic-pituitary-adrenal axis hyperactivity and psychosis: recovery during an 8-year followup. Am J Psychiatry 149: 1033-1039.

Cox ED, Hoffmann SC, DiMercurio BS, Wesley RA, Harlan DM, Kirk $\mathrm{AD}$ et al (2001). Cytokine polymorphic analyses indicates ethnic differences in the allelic distribution of interleukin-2 and interleukin-6. Transplantation 72: 720-726.

Dinan TG (1996). Serotonin and the regulation of hypothalamicpituitary-adrenal axis function. Life Sci 58: 1683-1694.

Ganguli R, Yang Z, Shurin G, Chengappa RKN, Brar JS, Gubbi AV et al (1994). Serum interleukin-6 concentration in schizophrenia: elevation associated with duration of illness. Psychiatry Res 51: $1-10$.

Ganguli R, Brar JS, Chengappa KNR, Deleo M, Yang ZW, Shurin G et al (1995). Mitogen-stimulated interleukin-2 production in never-medicated, first-episode schizophrenic patients. Arch Gen Psychiatry 52: 668-672.

Geddes J, Freemantle N, Harrison P, Bebbington P (2000). Atypical antipsychotics in the treatment of schizophrenia: systematic overview and meta-regression analysis. BMJ 321: 1371-1376.

Haddad JJ, Saade NE, Safieh-Garabedian B (2002). Cytokines and neuro-immune-endocrine interactions: a role for the hypothalamic-pituitary-adrenal revolving axis. J Neuroimmunol 133: 1-19.

Hanisch UK, Rowe W, Sharma S, Meaney MJ, Quirion R (1994). Hypothalamic-pituitary-adrenal activity during chronic central administration of interleukin-2. Endocrinology 135: 2465-2472.

Henneberg AE, Horter S, Ruffert S (1994). Increased prevalence of antibrain antibodies in the sera from schizophrenic patients. Schizophr Res 14: 15-22.

Hoffmann SC, Stanley EM, Cox ED, DiMercurio BS, Koziol DE, Harlan DM et al (2002). Ethnicity greatly influences cytokine gene polymorphism distribution. Am J Transplant 2: 560-567.

Jansen LM, Gispen-de Wied CC, Gademan PJ, De Jonge RC, van der Linden JA, Kahn RS (1998). Blunted cortisol response to a psychosocial stressor in schizophrenia. Schizophr Res 33: 87-94.

Janssen PA, Niemegeers CJ, Awouters F, Schellekens KH, Megens AA, Meert TF (1988). Pharmacology of risperidone (R 64 766), a new antipsychotic with serotonin-S2 and dopamine-D2 antagonistic properties. J Pharmacol Exp Ther 244: 685-693.

Kaneko M, Yokoyama F, Hoshino Y, Takahagi K, Murata S, Watanabe $M$ et al (1992). Hypothalamic-pituitary-adrenal axis function in chronic schizophrenia: association with clinical features. Neuropsychobiology 25: 1-7.

Kaneda Y, Fujii A, Ohmori T (2002). The hypothalamic-pituitaryadrenal axis in chronic schizophrenic patients long-term treated with neuroleptics. Prog Neuropsychopharmacol Biol Psychiatry 26: 935-938.

Kay SR, Fiszbein A, Opler LA (1987). The positive and negative syndrome scale (PANSS) for schizophrenia. Schizophr Bull 13: 261-276.

Kronfol Z, Remick DG (2000). Cytokines and the brain: implications for clinical psychiatry. Am J Psychiatry 157: 683-694.

Lammers CH, Garcia-Borreguero D, Schmider J, Gotthardt U, Dettling M, Holsboer F et al (1995). Combined dexamethasone/ 
corticotropin-releasing hormone test in patients with schizophrenia and in normal controls. Biol Psychiatry 38: 803-807.

Licinio J, Seibyl JP, Altemus M, Charney DS, Krystal JH (1993). Elevated CSF levels of interleukin-2 in neuroleptic-free schizophrenic patients. Am J Psychiatry 150: 1408-1410.

Lin A, Kenis G, Bignotti S, Tura GJ, De Jong R, Bosmans E et al (1998). The inflammatory response system in treatmentresistant schizophrenia: increased serum interleukin-6. Schizophr Res 32: 9-15.

Maes M, Bosmans E, Calabrese J, Smith R, Meltzer H (1995). Interleukin-2 and interleukin-6 in schizophrenia and mania: effects of neuroleptics and mood stablizers. J Psychiatric Res 29: 141-152.

Maes M, Bosmans E, Kenis G, DeJong R, Smith RS, Meltzer HY (1997). In vivo immunomodulatory effects of clozapine in schizophrenia. Schizophre Res 26: 221-225.

Maes M, Bocchio Chiavetto L, Bignotti S, Battisa Tura G, Pioli R, Boin $\mathrm{F}$ et al (2000). Effects of atypical antipsychotics on the inflammatory response system in schizophrenic patients resistant to treatment with typical neuroleptics. Eur Neuropsychopharmacol 10: 119-124.

Maes M, Bocchio Chiavetto L, Bignotti S, Battisa Tura GJ, Pioli R, Boin $\mathrm{F}$ et al (2002). Increased serum interleukin-8 and interleukin-10 in schizophrenic patients resistant to treatment with neuroleptics and the stimulatory effects of clozapine on serum leukemia inhibitory factor receptor. Schizophr Res 54: 281-291.

Marx CE, Lieberman JA (1998). Psychoneuroendocrinology of schizophrenia. Psychiatr Clin North Am 21: 413-434.

Meltzer HY, Lee MA, Jayathilake K (2001). The blunted plasma cortisol response to apomorphine and its relationship to treatment response in patients with schizophrenia. Neuropsychopharmacology 24: 278-290.

Muck-Seler D, Pivac N, Jakovljevic M, Brzovic Z (1999). Platelet serotonin, plasma cortisol, and dexamethasone suppression test in schizophrenic patients. Biol Psychiatry 45: 1433-1439.

Muller N, Hofschuster E, Ackenheil M, Eckstein R (1993). T-cells and psychopathology in schizophrenia: relationship to the outcome of neuroleptic therapy. Acta Psychiatr Scand 87: 66-71.

Muller N, Ackenheil M (1998). Psychoneuroimmunology and the cytokine action in the CNS: implications for psychiatric disorders. Prog Neuropsychopharmacol Biol Psychiatry 22: $1-33$.

Newcomer JW, Faustman WO, Whiteford HA, Moses Jr JA, Csernansky JG (1991). Symptomatology and cognitive impairment associate independently with post-dexamethasone cortisol concentrations in unmedicated schizophrenic patients. Biol Psychiatry 29: 855-864.

Rapaport MH, McAllister CG, Kim YS, Han JH, Pickar D, Nelson DL et al (1994). Increased serum soluble interleukin-2 receptors in Caucasian and Korean schizophrenic patients. Biol Psychiatry 35: 767-771.
Rapaport MH, McAllister CG, Pickar D, Tamarkin L, Kirch DG, Paul SM (1997). CSF IL-1 and IL-2 in medicated schizophrenic patients and normal volunteers. Schizophr Res 25: 123-129.

Sharma RP, Pandey GN, Janicak PG, Peterson J, Comaty JE, Davis JM (1988). The effect of diagnosis and age on the DST: a metaanalytic approach. Biol Psychiatry 24: 555-568.

Shirayama Y, Hashimoto K, Suzuki Y, Higuchi T (2002). Correlation of plasma neurosteroid levels to the severity of negative symptoms in male patients with schizophrenia. Schizophr Res 58: 69-74.

Song C, Lin AH, Kenis G, Bosmans E, Maes M (2000). Immunosuppressive effects of clozapine and haloperidol: enhanced production of the interleukin-1 receptor antagonist. Schizophr Res 42: 157-164.

Spangelo BL, Judd AM, Call GB, Zumwalt J, Gorospe WC (1995). Role of the cytokines in the hypothalamic-pituitary-adrenal and gonadal axes. Neuroimmunomodulation 2: 299-312.

Steensberg A, Fischer CP, Keller C, Moller K, Pedersen BK (2003). IL-6 enhances plasma IL-1ra, IL-10, and cortisol in humans. Am J Physiol Endocrinol Metab 285: 433-437.

Tandon R, Mazzara C, DeQuardo J, Craig KA, Meador-Woodruff JH, Goldman R et al (1991). Dexamethasone suppression test in schizophrenia: relationship to symptomatology, ventricular enlargement, and outcome. Biol Psychiatry 29: 953-964.

Walder DJ, Walker EF, Lewine RJ (2000). Cognitive functioning, cortisol release, and symptom severity in patients with schizophrenia. Biol Psychiatry 48: 1121-1132.

Walker EF, Diforio D (1997). Schizophrenia: a neural diathesisstress model. Psychol Rev 104: 667-685.

Wang J, Dunn AJ (1999). The role of interleukin-6 in the activation of the hypothalamo-pituitary-adrenocortical axis and brain indoleamines by endotoxin and interleukin-1 beta. Brain Res 815: 337-348.

Wirshing DA, Marshall Jr BD, Green MF, Mintz J, Marder SR, Wirshing WC (1999). Risperidone in treatment-refractory schizophrenia. Am J Psychiatry 156: 1374-1379.

Yeragani VK (1990). The incidence of abnormal dexamethasone suppression in schizophrenia: a review and a meta-analytic comparison with the incidence in normal controls. Can J Psychiatry 35: 128-132.

Zhang XY, Zhou DF, Cao LY, Zhang PY, WU GY, Shen YC (2001). Risperidone versus haloperidol in the treatment of acute exacerbations of chronic inpatients with schizophrenia: a randomized double-blind study. Int Clin Psychopharmacol 16: 325-330.

Zhang XY, Zhou DF, Zhang PY, Wu GY, Shen YC (2002a). Elevated interleukin-2, interleukin- 6 and interleukin-8 serum levels in neuroleptic-free schizophrenia: association with psychopathology. Schizophr Res 57: 247-258.

Zhang XY, Zhou DF, Cao LY, Zhang PY, Wu GY (2002b). Decreased production of interleukin-2 (IL-2), IL-2 secreting cells and CD4+ cells in medication-free patients with schizophrenia. J Psychiatric Res 36: 331-336. 